\title{
Americans' average radiation exposure
}

We live with radiation every day. We receive radiation exposures from cosmic rays, from outer space, from radon gas, and from other naturally radioactive elements in the earth. This is called natural background radiation. It includes the radiation we get from plants, animals, and from our own bodies.

We also are exposed to man-made sources of radiation, including medical and dental treatments, television sets and emission from coal-fired power plants. Generally, radiation exposures from man-made sources are only a fraction of those received from natural sources. One exception is high exposures used by doctors to treat cancer patients.

Each year in the United States, the average dose to people from natural and man-made radiation sources is about 360 millirem. A millirem is an extremely tiny amount of energy absorbed by tissues in the body.

\section{Where you live contributes to your exposure}

One of many factors contributing to radiation exposure is where you live. The level of radiation exposure in Nevada varies, being lower in the valley areas and higher in the elevated areas. The atmosphere is thinner at higher altitudes and allows more cosmic radiation exposure. The current average annual radiation dose to persons living in the Amargosa Valley is around 400 millirem some 40 millirem more than the national average.

\section{Protecting the public from repository radiation}

Protection of the public is of utmost importance to the United States Department of Energy (DOE). The repository design is intended to meet or exceed strict federal regulatory standards for radiation exposures. There are primarily two different radiation exposures to the public that might be possible from having a repository for spent nuclear fuel and high-level radioactive waste. The first is from transporting the materials and the second is from the repository for the materials.

\section{Exposures from transportation are very low}

Estimates for radiation dose from transportation, based on the exposure of a person standing 100 feet from a vehicle that is carrying waste and moving 15 miles per hour, is about 0.0004 millirem. A person would receive 5,000 to 12,500 times more radiation dose on a round-trip flight from Los Angeles to New York on a commercial airline (2-5 millirem). If a person were to stand 100 feet from a transportation route 24 hours a day for 24 years, and were exposed to all truck shipments (approximately 50,000), that person would receive a total whole-body radiation dose of about 20 millirem. During the same 24-year timeframe, that same person would receive over 7,000 millirem from natural background radiation.

H:IFACTSHT \Amers' Ave. Rad. Expo, no footnotes, 4 Graphics30.12.doc.doc. New edits include Danny Gonzalez's review inputs, primarily around consistent use of "dose". GM inserted new subheads After 30.12 review, Dan kane had corrections on the round-trip flight correlation, and $600 \mathrm{mrem}$ to 660 . Gm sending to Danny Gonzalez for his info then to 30.12 finale because Dennis Williams signed for Steve Brocoum in the 30.12. 


\section{Exposures from a repository}

Radiation exposures from a repository are estimated by DOE as follows: during the first 10,000 years following the closing of the proposed repository, persons living in Amargosa Valley would receive little or no increase in radiation exposure from the repository. This community is referenced because water from Yucca Mountain flows toward the Amargosa Valley. Water is expected to be the vehicle that would move radioactive particles from a repository to the water table and from there to contact with people and the environment.

DOE estimates the maximum exposure to occur some 300,000 years after the repository is closed. At that time, it is possible that some people living in the Amargosa Valley could receive an additional 260 millirem per year. This would bring their total radiation dose to around 660 millirem per year.

To put this dose in perspective, 660 millirem is somewhat higher than the 360 millirem national average on a yearly basis but well below levels received by people living in other parts of the United States.

For example, people living in the northwest region of Washington state receive about 240 millirem per year, on average, from natural and man-made sources whereas residents of the southeast region of Washington state receive about 630 millirem per year, on average, from natural and man-made sources. The highest levels of exposure in Washington state are experienced by residents in the northeast region who receive doses of about 1,700 millirem per year, most of it from radon in the rock and soil.

\section{A commitment to looking for even greater safety}

Even though the projections for possible radiation exposure from a repository in the distant future are modest, DOE's scientists and engineers are continuing to look at ways to improve radiation protection from a repository. DOE has been studying Yucca Mountain for more than 15 years and will continue to study Yucca Mountain, to determine whether it is a suitable site for a repository. Moreover, if the site is found suitable, and a repository is recommended, approved and licensed, scientists will, for at least 100 years, keep an ongoing check that everything is functioning the way they predicted it would.

For continuing updates on the site characterization, and repository engineering and design efforts, call 1-800-225-6972 or visit our Web site at www.ymp.gov.

\section{Examples of possible annual doses}

\section{from common sources of radiation*}

H:IFACTSHT\Amers' Ave. Rad. Expo, no footnotes, 4 Graphics30.12.doc.doc. New edits include Danny Gonzalez's review inputs, primarily around consistent use of "dose". GM inserted new subheads After 30.12 review, Dan kane had corrections on the round-trip flight correlation, and $600 \mathrm{mrem}$ to 660 . Gm sending to Danny Gonzalez for his info then to 30.12 finale because Dennis Williams signed for Steve Brocoum in the 30.12. 
Where you live

Location: Las Vegas, Nevada (Natural background) 89 millirem or mrem

(Natural background radiation for Beatty, Nevada is $143 \mathrm{mrem}$. )

House Construction: For stone, concrete, or masonry building7-25 mrem

What you eat, drink, breathe

Food, Water, Air (Potassium 40**)(U.S. average)............... 25 mrem

World-wide weapons test fallout 4 mrem

\section{Medical}

One chest X-ray 10-39 mrem

(A lower gastrointestinal tract $\mathrm{X}$-ray is $\mathbf{5 0 0} \mathrm{mrem}$. A radiopharmaceutical exam is $300 \mathrm{mrem}$.)

How you live

Jet plane travel: For each 2,500 miles, add $1 \mathrm{mrem}$; round trip is $2-5 \mathrm{mrem}$, depending on altitude and shielding.

TV viewing: 3 hours per day 1 mrem

Cooking: With natural gas, add 6 mrem 6 mrem

Total annual dose for this example (numbers in bold) is $186 \mathrm{mrem}$. U.S. annual average dose is 360 mrem (includes U.S. average of $200 \mathrm{mrem}$ for radon***).

Most scientists agree on the internationally recognized guidelines for regulating radiation doses to protect the public and the environment. By using a philosophy that limits exposure to radiation to doses as low as reasonably achievable, doses are kept to levels less than the limits stipulated by the regulations. This approach is used by DOE and its contractors when evaluating potential exposures that might be received by members of the general public and people who work around radioactive materials.

*Doses are expressed in millirem, abbreviated as mrem, and are estimates only and vary at any given time.

**The half-life of potassium-40 is greater than 1 billion years.

$* * *$ Radon-222 has a half-life of 3.8 days.

H:IFACTSHT\Amers' Ave. Rad. Expo, no footnotes, 4 Graphics30.12.doc.doc. New edits include Danny Gonzalez's review inputs, primarily around consistent use of "dose". GM inserted new subheads After 30.12 review, Dan kane had corrections on the round-trip flight correlation, and $600 \mathrm{mrem}$ to 660 . Gm sending to Danny Gonzalez for his info then to 30.12 finale because Dennis Williams signed for Steve Brocoum in the 30.12. 